\title{
Education and business requirements for the competencies and qualifications of modern tourism personnel
}

\author{
E. V. Rodionova ${ }^{1, a}$, Z.S. Zavyalova ${ }^{1}$, Baggio Rodolfo ${ }^{2}$, P.A. Arlyapova ${ }^{1}$ \\ ${ }^{1}$ Tomsk Polytechnic University, 634050 Lenin Avenue, 30, Tomsk, Russia \\ ${ }^{2}$ Bocconi University, Via Sarfatti, 25, Milano, Italy
}

\begin{abstract}
The modern stage of tourism development is characterized by a high level of differentiation of professional activity. It influences the increasing requirements towards the range of competencies and qualifications of tourism personnel. To find out the main directions of modernization of professional education programs it is necessary to monitor and systemize the requirements of the employers in the tourism sector. The authors carried out an expert survey and analysed the data gathered. Based on the results of the survey the main directions of modernization were described. It has been found out that a practiceoriented approach appears to be advantageous as a basis of modernization of educational programmes. The integration of business and education entities might contribute to the process of making education practiceoriented.
\end{abstract}

\section{Introduction}

Nowadays, Russia faces a variety of changes in all spheres of life that reflect its being in a state of transition to the informational stage of society. The Russian economy and education have also been going through modernization as the two major factors of the new society. In tourism, optimization of the system of additional education is of particular relevance as the dynamic tourism market, individualized consumption, and a specific character of tourist services require continuous development of additional qualifications. The effective additional educational programs can be worked out on the basis of the integration of the business and educational communities.

Many research issues in tourism are widely covered in the national and foreign press. Historical and current studies in the field of tourism belong to M. Birzhakov. The issues of scientific and educational aspects of tourism are presented in the works of V. Kvartalny. As for the foreign authors, the fundamental research belongs to P. Murphy, R. Butler. Modern aspects of tourism (such as place branding, electronic tourism, etc.) are investigated by F. Kotler, K. Spirou, R. Baggio, K. Dinny, A. Lew. S. Anholt is known for his research on the national rebranding of Russia. Contribution to education in tourism studies is also made by H. Halkier, and Michael Mair who concentrated on regional tourism development and problem-based learning (PBL)[1-9].
This research focuses on ways of modernization of additional professional training in the tourism sector on the basis of the integrated requirements of stakeholders.

\section{Materials and methods}

The research methodology is a theoretical analysis of the principles of modern professional education in tourism, and such empirical methods as expert interviews, focus groups. The authors conducted a study called "What do business and government think of the content and method of training in tourism?" (Hereinafter we use the results of research conducted by the members of the TEMPUS project «A Network of Continuing Education in Tourism").

Analysis of the existing training system of the tourist industry in the Russian Federation and abroad (Hereinafter, we use the results of the research conducted by members of the TEMPUS project «Network of Continuing Education in Tourism") has shown that the implementation of programs of additional professional training of tourism personnel should consider the following methodological principles:

- a high level of theoretical training, taking into account trends of modern social development, and inviting leading national and international experts to lecture;

- development of analytical skills, the use of projects aimed at practical application of modern methods and technologies of tourist enterprises;

\footnotetext{
a Corresponding author: eva@tpu.ru
} 
- development of skills of integrated analysis of tourism enterprises and dynamics of the tourist market;

- a student-centred approach to the participants of the educational process aimed at developing a responsible attitude towards the results of their professional activity;

- self-education, which puts the emphasis on the organisation of professional activities, focused on continuous professional self-improvement [10].

Researchers record a gap between social theories of tourism practices [11,12]. Therefore, the system of training and retraining of tourism personnel should be based on the requirements and expectations of the tourism industry itself. Monitoring, systematization and integration of the requirements of the state, employers, potential customers and the students themselves in the basic training program will help to resolve the contradictions of all actors of the tourist market and improve the quality of its functioning in the future $[13,14]$. Accordingly, it is necessary to identify the requirements of the following communities:

- representatives of business and authorities of tourism regions,

- the educational community.

Within this study, the authors have conducted 12 expert interviews and 62 formal interviews. We interviewed 12 experts, 8 of them are heads of travel agencies, 4 are the executive branch of the city and the region. The expert interview questionnaire was divided into three conceptual blocks: the first block was structured to find out the opinion about the necessity of special education for the staff working in the tourism sector, the second deals with the qualifications required for tourism personnel and the third one concerns the best forms of education to use.

62 formal interviews were conducted to find out what the heads of travel agencies think about the relevance and type of education for tourism personnel. The type of sampling used is the array method.

\section{Results and discussion}

Block 1. It was noted that the tourism industry employs people with very diverse backgrounds, but the priority of liberal education, namely socio-economic, is obvious. The interview allowed revealing two specific features about the existing requirements for the training of employees engaged in the tourism industry:

1.there is need for special education when an office staff member is promoted or when his/her specialization is established;

2. recently (in the last 2-5 years) the need for special education has increased, which is associated primarily with the development and complication (diversification) of the tourism industry.

Comparison of the efficiency of employees with special education and those without it revealed that the difference is evident at the initial stage of work and in respect of career opportunities. At the initial stage, workers with special education adapt to working conditions quickly ("smoothly drawn into work because they did it in practice while learning"), and, when promoted, they switch to new activities far easier.
On the question of the necessity of special education there was no disagreement - absolutely all of the experts claimed it was necessary. But as to the direction in which it must develop, there were two opinions:

1. Special education in tourism should be uniform i.e., it should have universal standards ("people who got one education should not have different skills").

2. Training should be more narrowly focused, i.e., there should be specialized courses aimed at obtaining the narrow knowledge, such as, for instance, knowledge of the regulatory framework of tourist activity in the particular area ("I need a man who would specialize in legal matters, and there is no need to teach him sales techniques").

Block 2. In general, the issue of basic skills of tourism personnel had the following groups of answers:

- knowledge and strategic thinking skills (skills of the competitive analysis, the ability to calculate risks, the ability to compute and predict the effectiveness of activities);

- highly specialized knowledge and skills (the ability to make a tour package and calculate its value, knowledge of a legal aspect in tourism, the ability to book);

- skills of effective communication (listening, guessing customer needs, selling products) ("For the manager, it is important to listen carefully - to understand what the client wants and make him/her a suitable offer - it is important that the client was satisfied with the trip, and, and the way s/he was treated in the agency").

The need for these skills was associated with the type of work. Experts divided all staff, involved in the tourism sector, into three key groups: managers (1), heads of departments (specialists) (2), staff working with customers (3).

It was also noted that the specialization options in the company depend on the type of enterprise. The tour operator organization identifies the following areas: a tourism product expert, a booking specialist (mentioned separately since in today's market this type of specialists is in demand particularly), a specialist in the promotion of tourism products (a promotion manager), a director. The travel agency identifies the following types of experts: a sales manager, a travel agent, an expert on visa provision, a head of a group of tourists, an area manager, a director.

Regarding the qualifications required for these groups there were two points of view. According to the first one, largely expressed by the representatives of the executive power, in the case of career promotion the qualification must expand, i.e. highly-qualified leaders must know all that is necessary for the effective organization and supervision of the staff; in addition, they must have the skills of strategic thinking. Thus, the head should ideally be a person with a wide professional outlook. In this vein, it was suggested that good leaders should be constantly improving their skills. The middle management should know its own specialization, for example, a specialist on visa provision must have the knowledge of the regulatory aspect of tourism activities and skills of business negotiations. As to a head of a 
group of tourists, the most important skills are knowledge of psychology, fundamentals of communication and intercultural communication, as well as the ability to deal with complaints of the customers. For lower-level personnel ("clerks") the main qualities are responsibility, sense of duty and a basic knowledge of the tourism business - qualification requirements for them are universal. These requirements are necessary to work in tourism industry, regardless of the position. Among these universal characteristics there were pointed out: language skills, effective communication skills, knowledge of the tourism terminology and a basic legal aspect of tourism activity. It should be mentioned that in today's market a greater share of travel companies are small businesses, the number of employees is quite small (5-10 people), respectively; in such enterprises, one employee performs various types of work.

According to the second point of view, the supervisor does not have to know of all the nuances of the activities of his/her subordinates. The main tasks of the head are strategic and operational management of the company to create conditions for efficient operation, staffing, coordination of different areas, and control over the company.

Block 3. In most cases, the experts noted that employees in the tourism sector have to get a special higher education, but it should be noted that, first of all, the emphasis was put on higher education with a major in humanities or economics. This is explained mainly by the fact that higher education provides a person with the ability to think logically, analyse a problem situation comprehensively, and give reasons for one's position. ("Such a person is able to see far beyond the surface, and is easier to rely on").

The existing forms of education were evaluated positively in general, although different estimates were given in respect of educational reforms, namely the shift from a five-year training scheme to " $4+2$ " (bachelor and master's training).

On account of the method of training, it can be noted that the representatives of both business and government have highlighted the need for the prevalence of the practice, especially in the last years of higher education, and for additional professional education (APE). It was pointed out that problem-based learning seems promising as a basic method of APE, since it provides proper relationship of theory and practice. Two experts from the executive branch stressed the need to focus on overseas experience, because it is necessary for the formation of broader strategic thinking. ("In the present situation in tourism we need a breakthrough, and if you learn from local practices, it is possible to get used to the existing patterns - and this will lead to constant movement in a vicious circle. To go beyond it, we need a fundamentally new look - a look from the outside - it can only be achieved by combining modern theory and international experience").

The experts pointed out that the real situation does not correspond to the desired one - there is a bias towards theoretical knowledge and the gap between the practical and theoretical part of the training.
Along with the expert interviews, we conducted 62 formal interviews with the head of travel agencies. Concerning the relevance of special education for tourism professionals, it was found out that the vast majority (43 out of 62) considered it as necessary. Twelve (12) managers chose "another variant". Eight (8) pointed out that the need for special education depends upon the position, three (3) were inclined to think that sometimes broad experience is more important than special education. All respondents paid attention to the education of the employee during the job interview. For sixteen (16) of sixty two (62) respondents education is not the most important factor when choosing a candidate. Regarding the type of education the interview revealed the following priorities: the most popular is the higher professional education (53), the second place belongs to the additional professional education (retraining) (39), and the third place is taken by the secondary vocational education (24). Five (5) respondents do not pay attention to the type of education.

\section{Conclusion}

The results of our study have shown that absolutely all the representatives of the tourism market agree that there is a need for modernization and development of vocational education in the field of tourism. Several experts noted that education should be more standardized, i.e. there must be universal standards in accordance with which the staff trained within the same educational programs in tourism would have a comparable set of professional knowledge and skills. On the other hand, training should be more narrowly focused, i.e. there is a need for specialized courses aimed at obtaining the narrow knowledge, such as knowledge of the regulatory framework of tourist activity. We also emphasize that business representatives noted the need for practical orientation of the content of educational programs. Graduates must be prepared to work in a real tourism market. To introduce a practice-oriented approach in education, it is necessary to build close relationships among business representatives and the education community, such as the introduction of methods of problem-based learning, master classes by leading international experts, joint work of the business community and students on tourist projects to develop the domestic tourism in the region [15].

Our monitoring of additional training programs was based on the following categories as keywords for the analysis:

APE subjects;

structural unit on the basis of which the re-training is offered;

coordinating unit;

general concept of the program;

curricula;

documents issued as a result of program completion.

The study allowed us to reveal the main problems of Russian APE in tourism. 
Table 1. Main problems of Russian APE in tourism

\begin{tabular}{|c|c|c|c|c|c|c|c|}
\hline 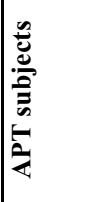 & $\begin{array}{ll} \\
0\end{array}$ & 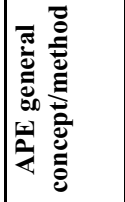 & 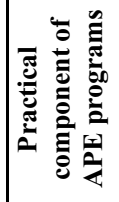 & 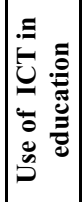 & 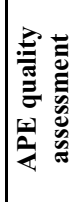 & 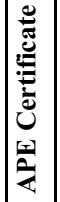 & U \\
\hline 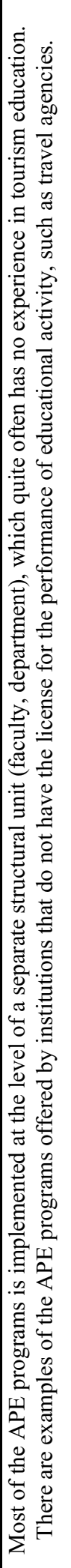 & 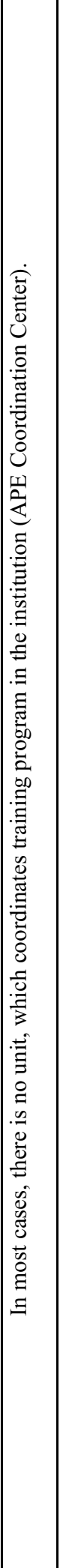 & 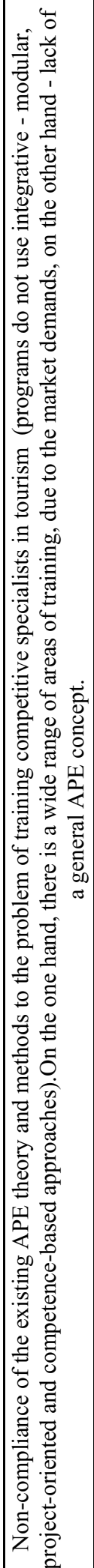 & 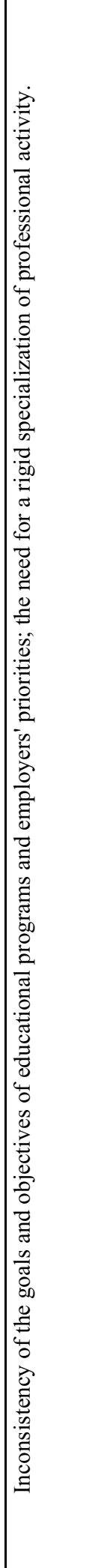 & 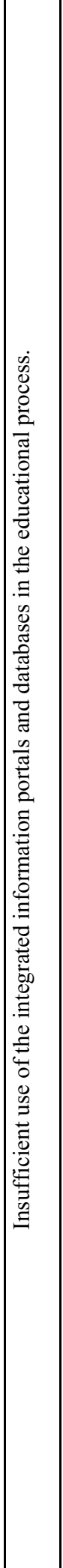 & 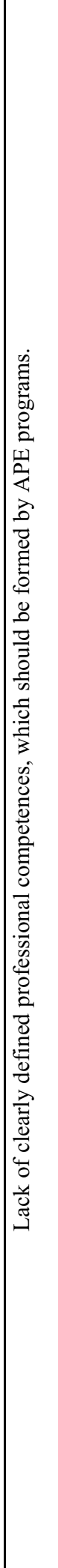 & 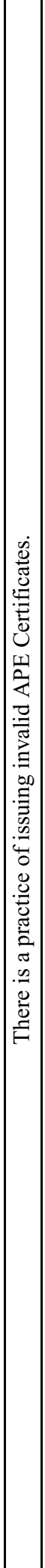 & 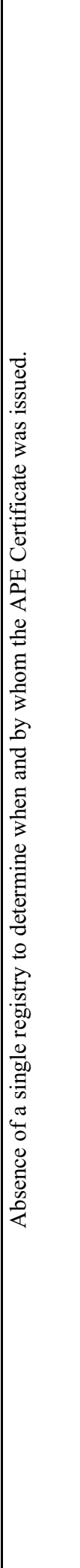 \\
\hline
\end{tabular}

The basis for this research was also actively promoted online resources of the institutions offering APE programs in Russia. We identified and monitored more than 25 of such online agencies in addition to the mentioned above in-depth interviews with the heads of relevant sections and departments of Russian educational institutions implementing the APE programs in tourism, including representatives of universities and members of the Association of Tourism and Service.

We believe that the result of this study complemented with the requirements of potential consumers of tourism services (the further research is planned by the authors) will help to identify the main directions of the modernization of APE programs in tourism.

\section{References}

1. H. Halkier, Eur. Plann. Stud., 20 (11), (2012)

2. B.S. Blichfeldt, H. Halkier, Eur. Plann. Stud, 22 (8), (2014)

3. H. Halkier, M. Kozak, B. Svensson, Eur. Plann. Stud., 22 (8), (2014)

4. H. Halkier, L. James, M. Dahlström, J. Manniche, Eur. Plann. Stud., 20 (11), (2012)

5. D. Ioannides, H. Halkier, A. Lew, Tour.Geogr, 16 (4), (2014)

6. G. Del Chiappa, R. Baggio, Journ.of Destin. Market. and Manag, 4 (3), (2015)

7. M.M. Mariani, R. Baggio, Anatol, 23 (1), (2012)

8. R. Baggio, Tour. Case Stud.: Manag. and Market (Iss., 2011)

9. R. Baggio, Tour. Plann. and Develop, 10 (2), (2013)

10. D.L. Konstantinovsky, Russ. Reform (Academia, 2002)

11. N. E. Zlokazova, Bull. of Intern. Organiz, 7-8 (22), (2008)

12. D.L. Konstantinovsky, Proceed. of the IV Ord. AllRuss. Congr. of Sociol (ROS, IP RAN AN RB ISPPI, 2012)

13. A. Radkov, Electr. Res. Access: http://www.akvobr.ru/radkov_kadry_dla_turizma.ht $\mathrm{ml}$

14. A.N. Furmankov, Addit. Prof. Educ, 9, (2008)

15. N.A. Kolodiy, Proc. - Soc. and Behav. Sci, 166, (2015) 